\title{
Applicability of a Moral Attitudes Toward Aggression Questionnaire (CAMA) in different German age Cohorts Compared with Other Cultures by a Structural Equivalence Analysis
}

\author{
J. Martin Ramirez*
}

Center for Conflict Studies, Nebrija University, Madrid, Spain

\begin{abstract}
The Questionnaire on Moral Attitudes toward Aggression (CAMA) focuses on moral attitudes toward aggression by asking respondents to rate combinations of different aggressive actions and situations in which these actions might be shown according to their respective justifiableness. Since its first applications by Lagerspetz and Westman in 1980 [1], it has been used in numerous cross-cultural studies across four continents for more than thirty years. The purpose of the studies here presented was to evaluate its applicability in a new cultural context, assessing if CAMA's data obtained in two different age cohorts from the German cultural context measured the same theoretical construct previously investigated across the other cultures (structural equivalence).

In the present studies 117 German university students (age range 19-38) and 141 German senior citizens (age range 60-94) were asked to complete a German translation of the CAMA. The structural equivalence was assessed by evaluating the fit of German data on previous factor structures via confirmatory factor analysis. A multi-group approach was being used to ascertain CAMA's applicability across different age groups. The structural fit was accessed by referring to factor structures that were derived from previous studies in the USA, Spain, Japan, and Hong Kong. These factor structures include separate three-factor models for types of aggressive actions and different two-factor models for situations in which these actions might be shown.

The results from both age groups of German population indicate the structural equivalence for the two factor models regarding defensive $v s$. non-defensive situations that justify aggressive actions. The equivalence for previous three-factor models regarding types of aggressive actions could not be shown in the German samples. Hence, adaptations concerning the assessment and theoretical models of the justification of aggressive actions in the German cultural context are being discussed.
\end{abstract}

Keywords: Attitudes toward aggression, cross-cultural studies, justification of aggression, structural equivalence.

\section{INTRODUCTION}

This is a short report on the assessment of the structural equivalence of a self-report on moral attitudes toward aggression, known by its Spanish initials CAMA (Cuestionario de Actitudes Morales sobre Agresión) applied to two different German age cohorts, focusing to both, situation and action models.

The Questionnaire is a self-report originally constructed by Lagerspetz and Westman [1], and subsequently revised and assembled by Ramirez et al., [2-6]. It has been applied in a cross-cultural approach across many different cultures of Eastern and Southern Europe, Africa, Asia, North and South America: in Finland [7], United Kingdom [8], Poland [3, 9], Spain [2, 5, 6], Japan and USA [10-12], Iran [13], Canada [14], India [15], Germany [16, 17], Hong-Kong [18], and Uruguay [19].

*Address correspondence to this author at the Center for Conflict Studies, Nebrija University, Madrid Spain; Tel: 3491 8444695;

Fax: 3491859 20 76; E-mail: jmartinramirez@ nebrija.es
The goal of the present study was to replicate it in different ages-subjects have been mainly young peoplewithin the same cultural context, because subpopulations defined in terms other than geography may also have different codes for the acceptance of aggression.

But in every cross-cultural study, like this series of crosscultural measurement of aggression, the question as to whether test scores obtained in different cultural populations can be interpreted in the same way across these populations has to be dealt with. "It cannot be taken for granted that scores obtained in one culture can be compared across cultural groups. Score differences observed in cross-cultural comparisons may have a partly or entirely different meaning than those in intracultural comparisons." [20, p. 131]. Whereas in the design of empirical studies it is often possible to be very selective in considering the choice of alternative explanations, the likelihood of this is extremely low in nonexperimental research designs, as cross-cultural studies: since groups that are compared in cross-cultural studies can hardly ever be seen as randomly matched on all background variables that are relevant for the constructs of interest, the 
assumption of their similarity across groups is unrealistic. Consequently, some measures have to be taken to increase the validity of cross-cultural inferences $[21,22]$.

And here comes an essential concept in cross-cultural research, known as "cultural equivalence", which refers to the level of comparability of measurement outcomes across different cultures. Is there an equivalence of meaning between different cultures? In order to address this question the same instrument is being applied in different cultural qroups. And if an instrument shows the same factor structure in all groups, then it implies the universal (i.e., cultureindependent) validity of the underlying psychological construct: there is structural equivalence [21-23].

If one wants to examine structural equivalence the use of several structural equation models may be considered, such as: exploratory factor analysis [Standard procedures for these target rotations are available e.g. in 24, 25], confirmatory factor analysis [cf. 26-28], or hierarchical confirmatory factor analysis [29].

The present study sought to clarify the applicability of this brief self-report for assessing the personal degree of approval of different aggressive acts in various instrumental and emotional-motivated situations, by people from two quite different German age cohorts. For this purpose, we have compared factor structures from these two German samples [29, 30] with other ones from USA, Spain, Japan (10-12) and Hong Kong (18), testing the equivalence with a hierarchical confirmatory factor analysis.

\section{METHODS}

\section{Participants:}

Two hundred and fifty-eight subjects living in Berlin participated in the study: 117 German university students (age range 19-38, with a mean of 23.1) and 141 German senior citizens (age range 60-94, with a mean of 81.6). Approximately three forths of them were females $(73.9 \%$ among the students, and $74.5 \%$ among the senior citizens). Participation was on a volunteer basis.

\section{Measurement:}

The CAMA questionnaire was administered in a German translation [16]. A 6 point scale (never justified $\langle->$ always justified) was used.

Since the degree of approval would depend on the qualities of the behavior observed, its items describe different types of aggressive acts in combination with diverse situations in which they may be conducted, Fig. (1) shows the different categories of actions and situations.

\section{Samples}

\begin{tabular}{|l|l|l|}
\hline & $\begin{array}{l}\text { University students } \\
\text { (Presented at the XVII Workshop Aggression } \\
\text { (Evers, Ramírez, Scheithauer, 2012) }\end{array}$ & $\begin{array}{l}\text { Senior citizens } \\
\text { (Presented at the XXXVI CICA } \\
\text { (Evers, Kohnert, Ramírez, Scheithauer, 2014) }\end{array}$ \\
\hline Number & 119 & 144 \\
\hline age & $23.1[19-38]$ & $81.6[60-94]$ \\
\hline females & $73.9 \%$ & $74.5 \%$ \\
\hline
\end{tabular}

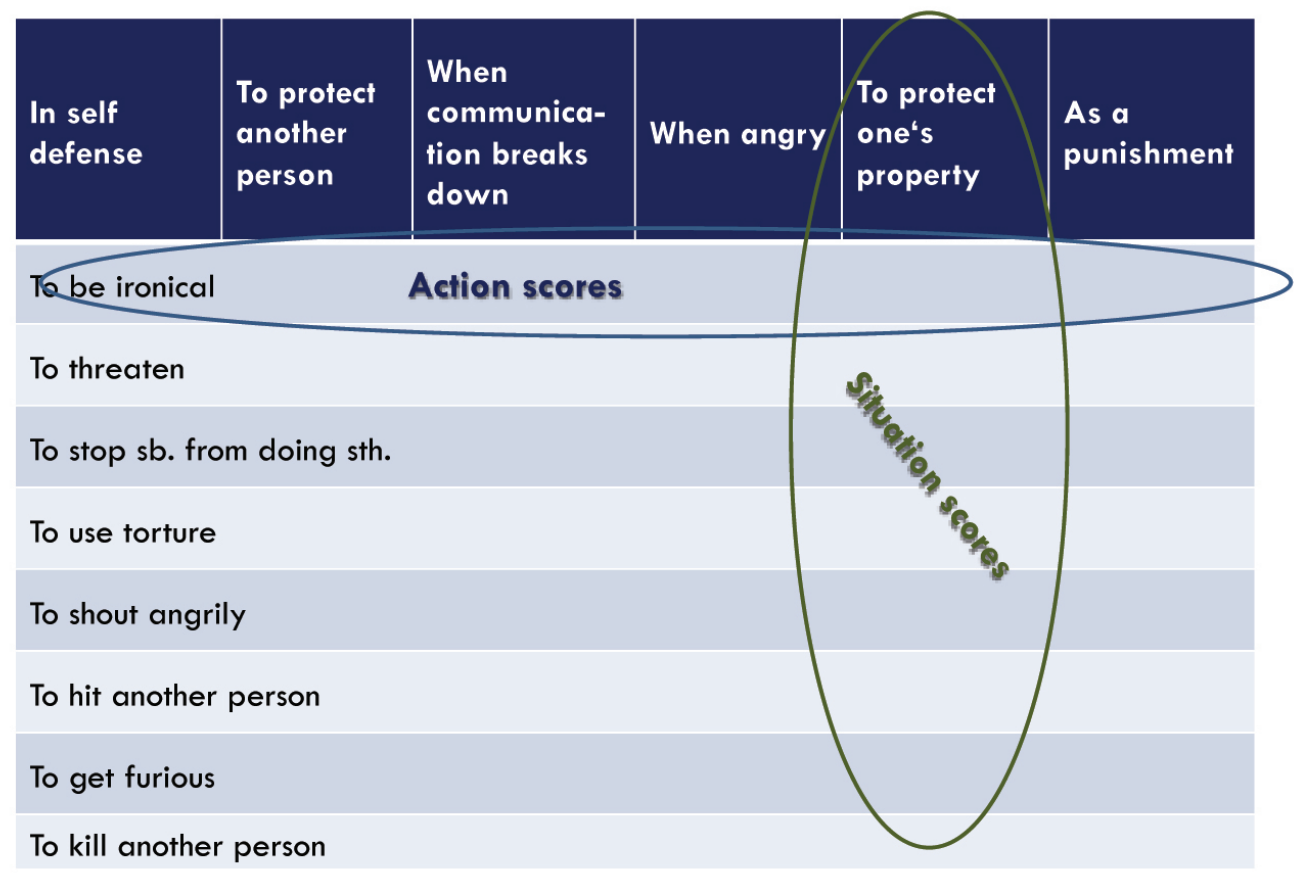

Fig. (1). CAMA action \& situation scores. 
The eight categories of aggressive acts are:

- To hit another person

- To kill another person

- To shout angrily

- To be ironical

- To use torture

- To get furious

- To threaten or

- To hinder another person from doing something

Each category of acts is accompanied by a list of six different circumstances in which the aggressive behavior may be justified, namely:

- in self-defense

- To protect another person

- in defense of one's property

- as a consequence of emotional agitation

- $\quad$ as a punishment or

- as a way of overcoming communication difficulties

\section{Statistical Method}

To assess the structural equivalence of the data Confirmatory Factor Analysis, based on factor structures obtained from previous studies [12, 18] were applied. Analyses were conducted with Mplus (Version 5.21). Estimators used were MLM and GLS. The focus of the analyses was the structural equivalence.

\section{RESULTS}

A confirmatory factorial analysis supported a significant fit for a bifactorial structure of the CAMA questionnaire, confirming a two-factor model. All items loaded significantly on their respective factors.

\section{Situations}

The factor structures from previous studies in the USA, Spain, Japan, and Hong Kong include the existence of a two factors model for situations in which these actions may be shown. The two factors correspond to defense and nondefense Fig. (2).

The present results indicate that there is also a structural equivalence for the two factor models regarding defensive $v s$. non-defensive situations that justify aggressive actions, in both age cohorts of German population, even if with a differential fit for old and young cohort: CFI (Comparative Fit Index) of 0.91 for students and 0.97 for senior citizens Fig. (3). Whereas the analysis with the student sample indicated a better fit for the second situation model, the first model showed better fit indices in the senior citizen sample. Concerning the fit indices for the student sample less weight was placed on the RMSEA (Root Mean Square Error of Approximation) than on the other indices since the RMSEA focuses on parsimony which is of less interest in the present study.

\section{Aggressive Acts}

The separate three-factors action model (physical aggression, indirect verbal aggression, direct verbal aggression) shown by previous factor structures in the USA,

\section{Sit I: USA / Hong Kong}

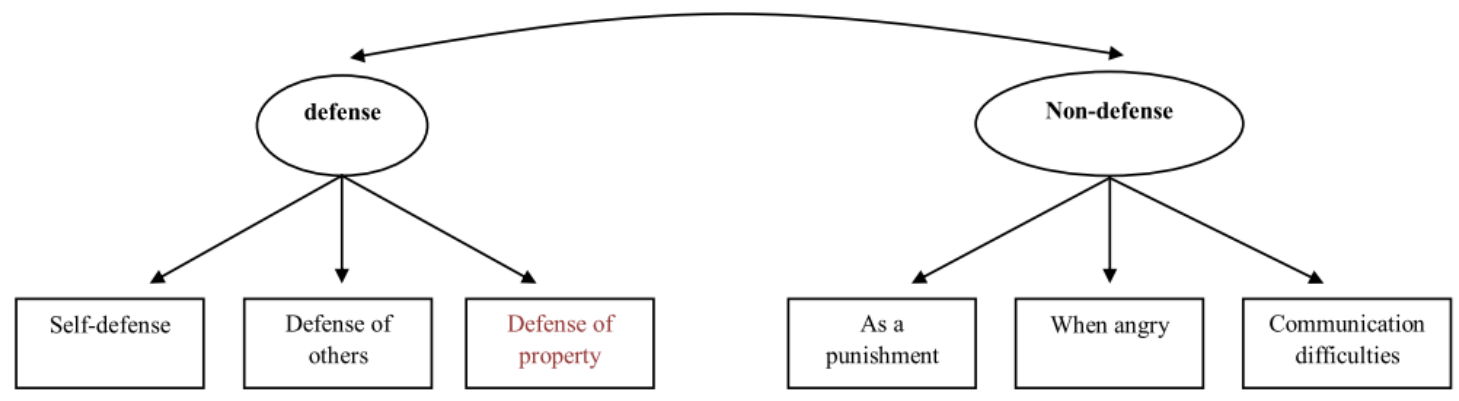

Sit II: Spain / Japan

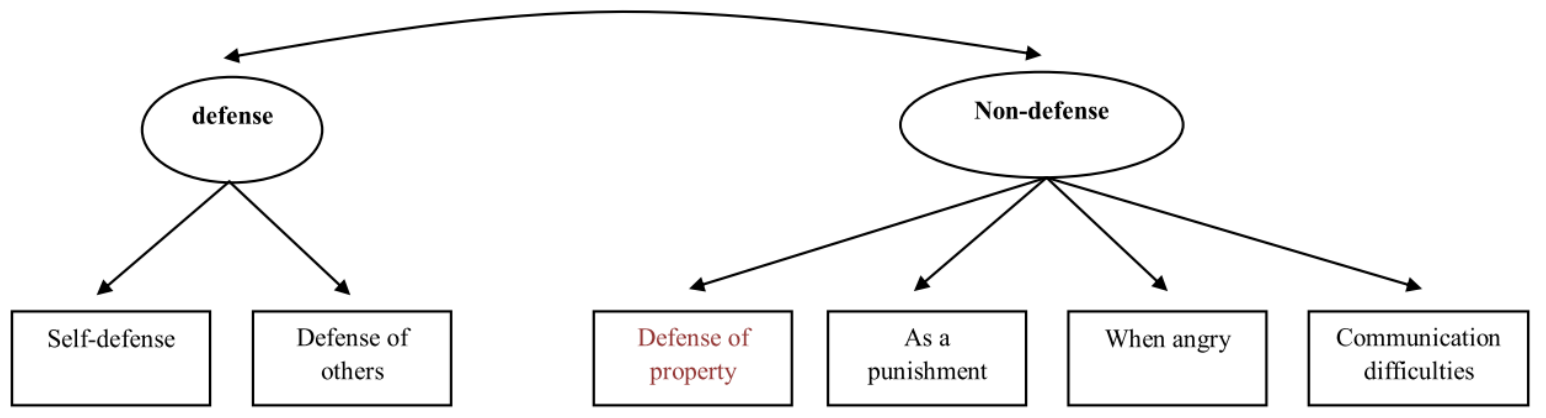

Fig. (2). Situation-Score models in different countries. 
Spain, Japan, and Hong Kong samples Fig. (4 and 5) did not fit for action models in the present German groups.

A Factor Analysis of the German student data [Evers, 2011] indicated a two-factor model regarding justification of aggressive actions: physical and non- physical aggression Fig. (6).
The newly developed action model for the university sample, was tested for differential fit in the senior citizen sample. Analyses were conducted for two separate models with and without irony because irony showed a comparatively low factor loading in the previous study [16]. Confirmatory Factor Analysis indicated no significant fir for

\section{Sit I: USA / Hong Kong}

CFI (Comparative Fit Index)

RMSEA (Root Mean Square Error of Approximation)

SRMR (Standardized Root Mean Square Residuals)

\begin{tabular}{|l|l|}
\hline University students & Senior citizens \\
\hline 0.91 & 0.97 \\
\hline 0.17 & 0.09 \\
\hline 0.08 & 0.04 \\
\hline
\end{tabular}

Sit II: Spain / Japan

\begin{tabular}{|l|l|l|}
\hline & University students & Senior citizens \\
\hline CFI & 0.92 & 0.92 \\
\hline SMSEA & 0.16 & 0.15 \\
\hline
\end{tabular}

Fig. (3). Results of situation-scores models in different countries.

Act I: USA / Spain

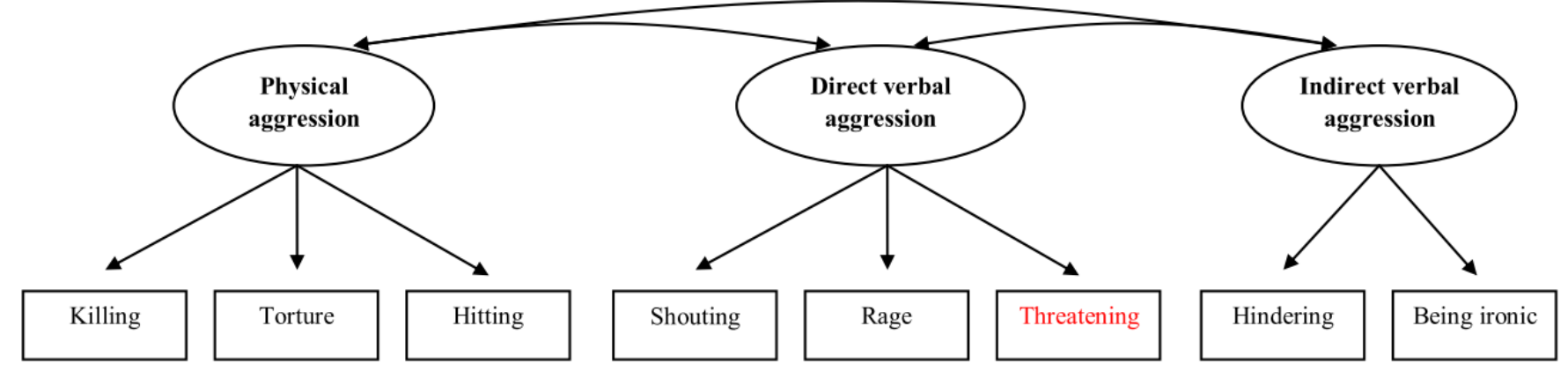

Act II: Japan

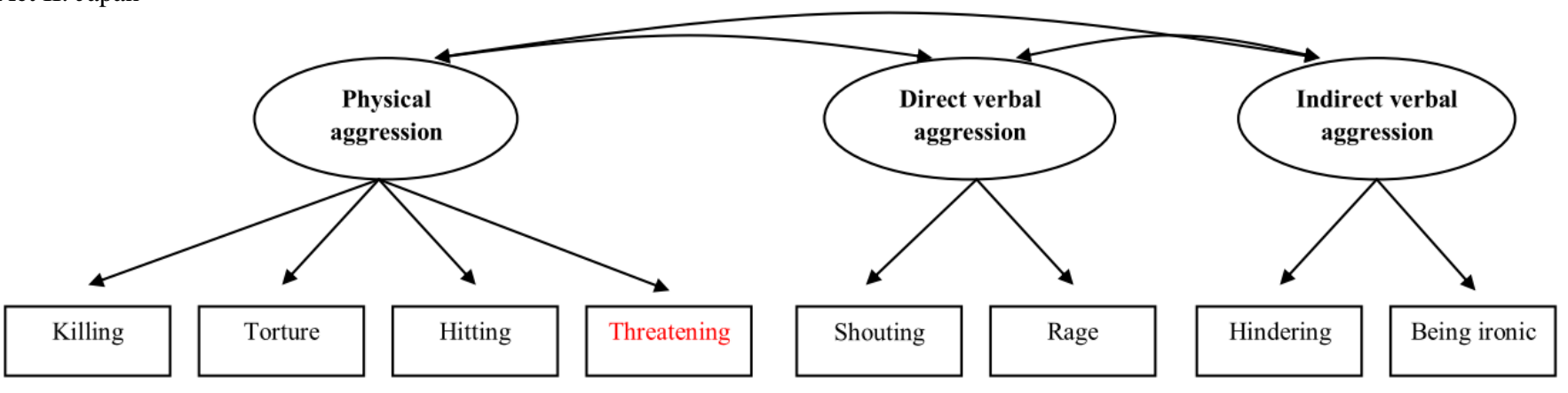

Fig. (4). Action-Score Models.

Act I: USA / Spain

\begin{tabular}{|l|l|l|}
\hline & University students & Senior citizens \\
\hline CFI & 0.88 & 0.84 \\
\hline RMSEA & 0.13 & 0.18 \\
\hline SRMR & 0.09 & 0.11 \\
\hline
\end{tabular}

Act II: Japan

\begin{tabular}{|l|l|l|}
\hline & University students & Senior citizens \\
\hline CFI & 0.88 & 0.68 \\
\hline RMSEA & 0.13 & 0.25 \\
\hline SRMR & 0.09 & 0.16 \\
\hline
\end{tabular}

Fig. (5). Results of the Action-Score Models. 


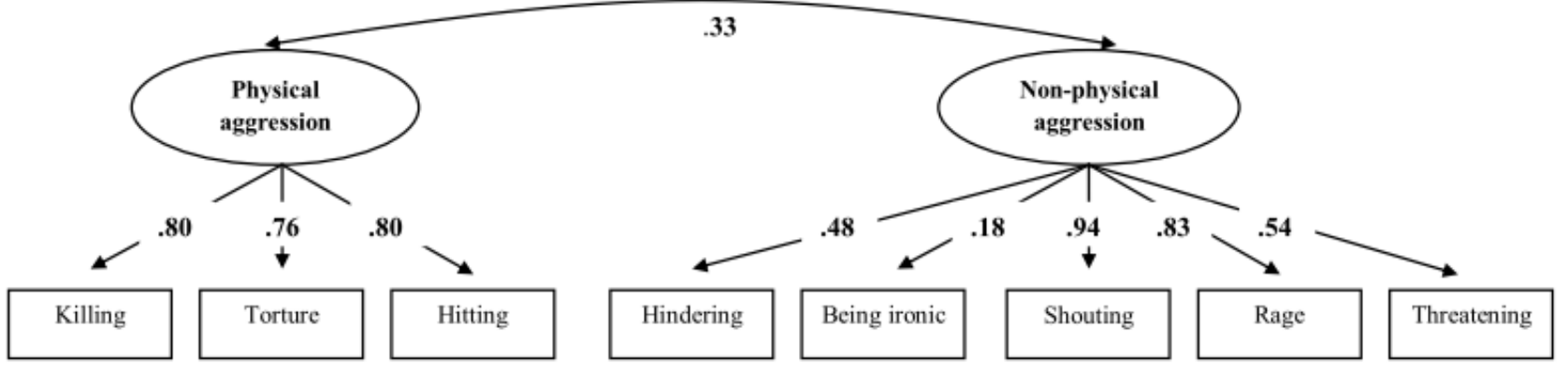

Fig. (6). Action-Score Model for the German context.

the newly developed German model in the senior citizens sample.

\section{DISCUSSION AND CONCLUSION}

The structural equivalence of CAMA in different German age cohorts compared with previous results in other cultures has been assessed. It has been focused to both, situation and action models.

The two factors situation model, corresponding to defense and non-defense, fit for the situations in which the aggressive actions might be shown, previously investigated across other cultures $[12,18]$, was also valid for the German population [30, 31], even if with a differential fit for old and young cohort.

But the three factors action model, corresponding to physical, indirect verbal, and direct verbal aggression, fit for the aggressive actions, previously investigated across other cultures $[12,18]$, did not fit for the present German samples. The structural analysis indicated a two-factors model regarding both German groups: physical and non- physical aggression.

The analyses of this study is not without limitations which may pose some problems if we want to generalize their results. First, the number of subjects of the different age utilized as samples may be too small for a comparative study. Second, both German samples may differ on education: one may assume that the seniors, in their $80 \mathrm{~s}$, would be less educated, as an average, than the present undergraduate population or at least they may differ in their educational background. Furthermore, results are based on the confirmation of second order model. Validation of the first-order-scale structure including analyses of CAMA's metric equivalence will be necessary before comparing difference score across nations.

Finally, some few suggestions for further assessment may be just enunciated: a) the investigation of the role of irony or sarcasm as an aggressive act or its exclusion as such assuming the inappropriateness of the item; b) the level of justification of specific combinations of actions and situations [e.g. 1, 6]; c) the use of scenarios as a method, as it has already used for assessing anger proneness and expression [32, 33]; or, d) hierarchies.

\section{CONFLICT OF INTEREST}

The author confirms that this article content has no conflict of interest.

\section{ACKNOWLEDGEMENTS}

The paper has been written during a stay of the author at Freie Universität Berlin (Arbeitsbereich Entwicklung swissenschaft \& Angewandte Entwicklungspsychologie, Fachbereich Erziehungswissenschaft und Psychologie Wissenschaftsbereich, Psychologie, Pf 19), sponsored by the Alexander von Humboldt Foundation.

The data were collected and statistically analyzed by Oliver Evers and Bettina Kohnert, for the achievement of their degree diplomas under the direction of prof. Herbert Scheithauer.

Previous reports were presented at the XVII. Workshop Aggression (Luxembourg July, 2012) and at the 36th CICA on Attitudes toward Conflict and Aggression, (Zielona Gora, Poland, June 2014).

\section{REFERENCES}

[1] Lagerspetz KMJ, Westman M. Moral approval of aggressive acts: a preliminary investigation. Aggress Behav 1980; 6: 119-30.

[2] Ramírez JM, Folgado LC. Attitudes toward aggression in four Spanish regions. Paper presented at III European ISRA, Parma. In: F. Le Moli, Ed. Multidisciplinary approaches to conflict and appeassement in animals and man. Istituto di Zoologia: Parma $1985 ;$ p.63.

[3] Fraczek A, Ramírez JM, Torchalska B. Attitudes toward interpersonal aggression: some further data and comments on the influence of cultural variables. III European ISRA, Parma. In: F. Le Moli, Ed. Multidisciplinary approaches to conflict and appeassement in animals and man, Istituto di Zoologia, Parma $1985 ;$ p. 182.

[4] Ramírez JM. Comparison of the degree to which aggression is acceptable in four Spanish regions. Chicago: Paper presented at the 7th Biennial Meeting of ISRA 1986.

[5] Ramírez JM. Similarities in attitudes toward interpersonal aggression in Finland, Poland, and Spain. J Soc Psychol 1991; 13: 737-9.

[6] Ramírez JM. Acceptability of aggression in four Spanish regions and a comparison with other European countries. Aggress Behav 1993; 19: 185-97.

[7] Lagerspetz KMJ, Björkqvist K, Björkqvist H, Lundman H. Moral approval of aggression and sex role identity in officer trainees, conscientious objectors to military service, and in a female reference group. Aggress Behav 1988; 14: 303-13.

[8] Benton D, Kumari N, Brain PF. Mild hypoglycaemia and questionnaire measures of aggression. Biol Psychol 1982; 14: 12935 .

[9] Fraczek A. Moral approval of aggressive acts: a Polish-Finish comparative study. J Cross Cult Psychol 1985; 3.

[10] Fujihara T, Kohyama T, Tanaka T-, Andreu JM, Ramirez JM. Attitude of American, Japanese and Spanish students toward interpersonal aggression. Human and animal aggression: sociocognitive and neurobiological determinants. Strasbourg 1996, p. 81 . 
[11] Ramírez JM, Fujihara T. Cross-cultural study of attitudes toward interpersonal aggression. Kwansei Gakuin Sociol Stud 1997; 78: 97-103.

[12] Fujihara T, Kohyama T, Andreu JM, Ramírez JM. Justification of interpersonal aggression in Japanese, American, and Spanish students. Aggress Behav 1999; 25: 185-95.

[13] Musazadeh Z. Agresión y su justificación: un estudio comparado de studiantes iraníes y españoles. Madrid: Universidad Complutense 1999.

[14] Ramírez JM, Bonniot-Cabanac M-C, Cabanac M. Can aggression provide pleasure? Eur Psychol 2005; 10: 136-45.

[15] Ramírez JM. Justification of aggression in several Asian and European countries with different religious and cultural backgrounds. Int J Behav Dev 2007; 31: 9-15.

[16] Evers O. Der CAMA Fragebogen zu aggressionsbezogenen Einstellungen: Überprüfung der Faktorenstruktur und Vorschläge zur Adaption für den deutschen Kulturkreis. Germany: Freie Universität Berlin 2011.

[17] Kohnert B. Rechtfertigung von Aggressionen bei Menschen ab einem Alter von 60 Jahren. Germany: Freie Universität Berlin 2014.

[18] Ramírez JM, Lai-chu AF, Alvarado JM, Millana L. Justification of emotional and instrumental aggression in Hong Kong and Spanish university students. Open Psychol J 2011; 4: 49-53.

[19] Fares NE, Ramírez JM, Cabrera JM, Lozano F, Salas F. Justification of physical and verbal aggression in uruguayan children, and adolescents. Open Psychol J 2011; 4(Suppl 1-M1): 45-54.

[20] van deVijver FJR, Tanzer NK. Bias and equivalence in crosscultural assessment: an overview. Revue européenne de psychologie appliquée 2004; 54: 119-35.

[21] Leung K, Van de Vijver FJR. Strategies for strengthening causal inferences in cross-cultural research: the consilience approach. $\mathrm{J}$ Cross Cult Manag 2008; 8: 145-69.

[22] van de Vijver FJ, Leung K. Equivalence and bias: a review of concepts, models, and data analytic procedures. In: Matsumoto DR, van de Vijver FJ, Eds. Culture and Psychology: cross-cultural research methods in psychology. New York: Cambridge University Press 2011; pp. 46-70.

[23] Poortinga YH. Equivalence of cross-cultural data: an overview of basic issues. Int J Psychol 1989, 24, 737-56.

[24] van deVijver FJR, Leung K. Methods and data analysis for crosscultural research. Newbury Park, CA: Sage 1997.

[25] Chan W, Ho RM, Leung K, Chan DKS, Yung YF. An alternative method for evaluating congruence coefficients with procrustes rotation: a bootstrap procedure. Psychol Methods 1999; 4: 378-402.

[26] Byrne BM. A Primer of LISREL: basic applications and programming for confirmatory factor analytic models. NewYork: Springer 1989.

[27] Byrne BM. Structural Equation Modelling with EQS and EQS/Windows: Basic Concepts, Applications, and Programming. Thousand Oaks, CA: Sage 1994.

[28] Byrne BM, Shavelson RJ, Muthén B. Testing for the equivalence of factor covariance and mean structures: the issue of partial measurement invariance. Psychol Bull 1989; 105: 456-66.

[29] Vandenberg RJ, Lance CE. A review and synthesis of the measurement invariance literature: suggestions, practices, and recommendations for organizational research. Organ Res Methods 2000; 2: 4-69.

[30] Evers O, Ramirez JM, Scheithauer H. Cultural equivalence of the questionnaire on moral attitudes toward aggression (CAMA) using structural equation modeling in a German university context. Luxembourg: $17^{\text {th }}$ Workshop Aggression 2012.

[31] Evers O, Kohnert B, Ramirez JM, Scheithauer H. Structural equivalence of the Questionnaire on Moral Attitudes toward Aggression (CAMA) in different German age groups. Poland: Oral $37^{\text {th }}$ CICA, International Conference on Conflict and Aggression, Zielona Gora 2014.

[32] Ramírez JM, Santisteban C, Fujihara T, Van Goozen, S. Differences between experiences of anger and readiness to angry action: a study of Japanese and Spanish students. Aggress Behav 2002; 23(6): 429-38.

[33] Schwartz S, Bardi A. Value hierarchies across cultures - taking a similarities perspective. J Cross Cult Psychol 2001; 32(3): 268-90. doi: $10.1177 / 0022022101032003002$. 